\title{
ZONEAMENTO AMBIENTAL DAS PAISAGENS: ESTUDO DE CASO DO ALTO CURSO DA BACIA HIDROGRÁFICA DO RIO SUCURIÚ, MATO GROSSO DO SUL, BRASIL
}

\author{
ENVIRONMENTAL ZONING OF LANDSCAPES: CASE \\ STUDY OF THE HIGH STREAM OF THE SUCURIÚ'S RIVER \\ WATERSHED, MATO GROSSO DO SUL, BRAZIL \\ ZONIFICACIÓN AMBIENTAL DE LOS PAISAJES: ESTUDIO DE \\ CASO DEL ALTO CURSO DE LA CUENCA HIDROGRÁFICA \\ DEL RIO SUCURIÚ, MATO GROSSO DO SUL, BRASIL \\ Cesar Cardoso Ferreira - Universidade Federal do Mato Grosso do Sul \\ Três Lagoas - Mato Grosso do Sul - Brasil \\ cesar.ufms@gmail.com
}

Edson Luís Piroli - Universidade do Estado de São Paulo - Ourinhos - São Paulo - Brasil
epiroli@gmail.com

\section{Resumo}

0 presente trabalho teve como objetivo propor sistematicamente o Zoneamento Ambiental das Paisagens do Alto Curso da Bacia Hidrográfica do Rio Sucuriú, com base nas unidades de paisagens para fins de conservação e preservação ambiental como forma de subsídio para o planejamento do manejo do uso da terra. Para alcançar tal objetivo foram executados procedimentos operacionais para processamento de dados orbitais, cadastrais e temáticos em ambiente de sistema de informação geográfica (SIG). Esses procedimentos foram divididos em três etapas: inventários/diagnóstico, correlação e propostas/prognóstico. Os resultados obtidos a partir da análise dos dados orbitais, fisiográficos e de matrizes demostraram que há necessidade de propor 0 zoneamento ambiental das paisagens associado à elaboração de propostas voltadas para o manejo do uso da terra para a preservação e conservação dos recursos naturais.

Palavras-chave: planejamento ambiental, conservação e preservação.

\section{Abstract}

This study aimed to systematically propose the environmental zoning of the landscapes of the Upper Course of the River Basin Sucuriú based on landscape units for conservation and environmental protection purposes with actions aimed at the management planning of land use. To achieve the goal were executed operating procedures for processing orbital, cadastral and thematic data in a Geographic Information System (GIS). Such procedures were divided into three steps: inventory/diagnosis, correlation and proposals/prognosis. The results from the analysis of the orbital, physiographic and matrices data have showed that there is a need to propose the environmental zoning of the landscapes involved in the preparation of proposals aiming at the control of land the preservation and conservation of natural resources.

Keywords: environmental planning, conservation and preservation.

\section{Resumen}

Este estudio tuvo como objetivo proponer sistemáticamente la zonificación ambiental de los paisajes del Alto Curso de la Cuenca Hidrográfica del río Sucuriú, basado en unidades de paisajes con fines de conservación y preservación del medio ambiente como forma de auxiliar la planificación de la gestión del uso del suelo. 
Para lograr ese objetivo se ejecutaron procedimientos operativos para el procesamiento de datos orbitales, catastrales y temáticos en el ambiente de un sistema de información geográfica (SIG). Esos procedimientos se dividieron en tres etapas: inventarios/diagnóstico, correlación y propuestas/pronóstico. Los resultados obtenidos a partir del análisis de los datos de satélite, fisiográficos y matrices demostraron que es necesario proponer la zonificación ambiental de los paisajes asociada a la elaboración de propuestas destinadas al control de uso de la tierra para la preservación y conservación de los recursos naturales.

Palabras-clave: planificación ambiental, conservación y preservación.

Introdução

A bacia hidrográfica é uma unidade considerada ideal para análises e estudos na temática ambiental. De acordo com Siqueira e Silva (2011), a bacia hidrográfica é utilizada como um modelo abrangente para entender os ecossistemas tendo em vista a interação dos ambientes aquáticos com os aspectos geológicos, pedológicos, climáticos, florísticos e de uso e cobertura da terra interagindo com processos bióticos e abióticos.

A bacia hidrográfica do rio Sucuriú é uma das principais Unidades de Planejamento e Gerenciamento (UPGs) do Estado de Mato Grosso do Sul, uma vez que desemboca no rio Paraná e contribui para a sua disponibilidade hídrica.Com essa interação de água entre rios, os padrões qualitativos e quantitativos da água no rio Paraná estão fortemente relacionados com as ações antrópicas e naturais às quais estão sujeitas a bacia hidrográfica do rio Sucuriú.

Com relação aos aspectos físicos naturais, o alto curso da bacia hidrográfica do rio Sucuriú destaca-se pelas diferenças altimétricas e geomorfológicas, apresentando planaltos bem definidos localizados sobre solos férteis apropriados para a produção agrícola. Apresenta vertentes íngremes caracterizadas pelos anfiteatros, que são cobertos por vegetação de cerrado, nos quais se concentram as nascentes dos afluentes do rio Sucuriú. A área apresenta, ainda, planícies cobertas por vegetação de varjão e por veredas. De maneira geral, a cobertura vegetal nativa é distribuída por toda área, estando concentrada, principalmente, na porção norte, caracterizando-a como com boas condições ecológicas.

Com relação à disposição político-administrativa, na Bacia estão inseridos parcialmente os municípios de Costa Rica, Paraíso das Águas, Chapadão do Sul, Inocência, Água Clara e Cassilândia. Destes, os três primeiros possuem suas áreas urbanas e sedes administrativas no interior do limite da área de estudo. Costa Rica e Paraíso das Águas fazem uso das águas do rio Sucuriú e Chapadão do Sul usa águas dos afluentes deste rio para abastecimento de seus núcleos urbanos. 
A principal atividade produtiva na bacia estudada é a agricultura, com predominância para as culturas temporárias mecanizadas, principalmente no município de Chapadão do Sul, que tem sua base econômica quase que totalmente voltada para esta atividade, e que é considerado um dos maiores produtores agrícolas do Estado de Mato Grosso do Sul. Isto é confirmado com a análise do Produto Interno Bruto (PIB) per capita, onde se sobressai como maior PIB per capita regional em 2011 (equivalente a $\mathrm{R} \$ 40.106,00$ ), tendo uma participação de 3,72\% na economia Estadual, mesmo com um baixo coeficiente populacional (2,47\% da população residente em Mato Grosso do Sul).

Outra atividade econômica relevante na área e que tem impactos ambientais importantes é a produção energética hidráulica a partir de sete Pequenas Centrais Hidroelétricas (PCH) distribuídas no rio Sucuriú e em seus afluentes. Além desta, ao longo das margens dos rios da bacia estão localizados vários atrativos turísticos que usam a água como fator de desenvolvimento da atividade, sobretudo em locais onde existem quedas d'água.

Cabe ressaltar, que a diversidade no uso e cobertura da terra é baseada nas culturas agrícolas, nas pastagens e nas áreas urbanas que são associadas a significativos desordenamentos pontuais e gerais, como erosão, assoreamento, deposição irregular de resíduos sólidos e perda da biodiversidade. Tais apontamentos confirmam o observado em estudos realizados anteriormente na região, como os de Ferreira (2015) que analisou vulnerabilidade ambiental, Silva et al. (2012) que avaliaram uso e ocupação da terra e Áreas de Preservação Permanente de nascentes, Quirino, Rocha e Moura. (2013) que estudaram resíduos sólidos, e Águas (2015) que analisou a influência direta e indireta da PCH Costa Rica.

Levando em consideração esses aspectos, acentua-se a importância do zoneamento ambiental das paisagens,por ser este um instrumento para classificar áreas de interesse em porções/zonas de acordo com padrões e características do ambiente. A paisagem, desta forma, serviu como categoria de análise para auxiliar no entendimento e identificação das particularidades e singularidades naturais e antrópicas da área de estudo. Além disso, possibilitou a visão da importância e da funcionalidade das unidades de paisagem no sistema hidrográfico estudado.

Silva e Rodriguez (2011) dizem que o zoneamento ambiental das paisagens é um importante instrumento de planejamento e de gerenciamento ambiental, por considerar as diversidades dos ambientes, as condições e os diferentes graus de restrições a serem observados em 
áreas que podem ser utilizadas para proteção e conservação dos recursos naturais, de modo a priorizar a sustentabilidade da região.

Nesse sentido, Valente (2005, p. 17), argumenta que "a priorização de áreas representa um dos métodos mais efetivos e econômicos no manejo de bacias hidrográficas”. Sua eficácia é baseada principalmente na capacidade de interação e análise dos diferentes dados que compõem as paisagens. O processo de priorização de áreas muitas vezes requer uma abordagem multicriterial, técnica empregada para a tomada de decisão que pode ser medida e avaliada por critérios. Deste modo, entende-se que a geração de áreas prioritárias para zoneamento ambiental das paisagens no alto curso da bacia hidrográfica do rio Sucuriú, por meio de avaliação de multicritérios de forma sistemática, pode contribuir para geração de planos e propostas de melhoria para o ordenamento territorial da área.

O zoneamento ambiental visa a definição de áreas conforme suas suscetibilidades e potencialidades. Tal processo resulta em orientações desenvolvidas para a limitação no uso conforme o grau de critérios adotados. Desta maneira, destaca-se a relevância de estudos nesse sentido, pois são formas de planejar e organizar áreas com potencial para degradação e revitalizar áreas já degradadas. Além disso, podem auxiliar a preservar e conservar áreas com potencial ecológico.

Assim, justifica-se a análise integrada da paisagem para fins de diagnóstico e prognóstico como zoneamento ambiental que tem como finalidade mitigar ações prejudiciais em termos socioambientais. Manosso (2009) comenta que com o diagnóstico da paisagem são reconhecidos os seus elementos principais, sua estrutura e seu funcionamento, e que a partir disso se pode criar mecanismos mais hábeis para subsidiar o planejamento e as ações dos sistemas socioeconômicos que exploram o potencial ecológico dessa paisagem.

\section{Materiais e métodos}

O alto curso da bacia hidrográfica do rio Sucuriú está totalmente inserido na área do Estado de Mato Grosso do Sul (Figura 1). O rio Sucuriú é afluente da margem direita do rio Paraná que, por sua vez, é afluente do rio da Prata. A área estudada abrange $11.193 \mathrm{~km}^{2}$ e é caracterizada, principalmente, por três tipos de formações de vegetação nativa: formação campestre, formação savânica e a formação florestal localizadas em área onde ocorre o predomínio de latossolos e neossolos quartzarênicos em 
substrato geológico predominante de arenitos. Com base na Teoria Geral dos Sistemas (proposta por Bertallanfy, 1977) e na abordagem sistêmica discutida por Christofoletti (1999) e Rodríguez, Silva e Cavalcanti (2010), caracterizou-se o alto curso da bacia hidrográfica do rio Sucuriú como Sistema, suas homogeneidades como Subsistemas e suas partes componentes como unidades paisagísticas.

Figura 1 - Localização do alto curso da bacia hidrográfica do rio Sucuriú.

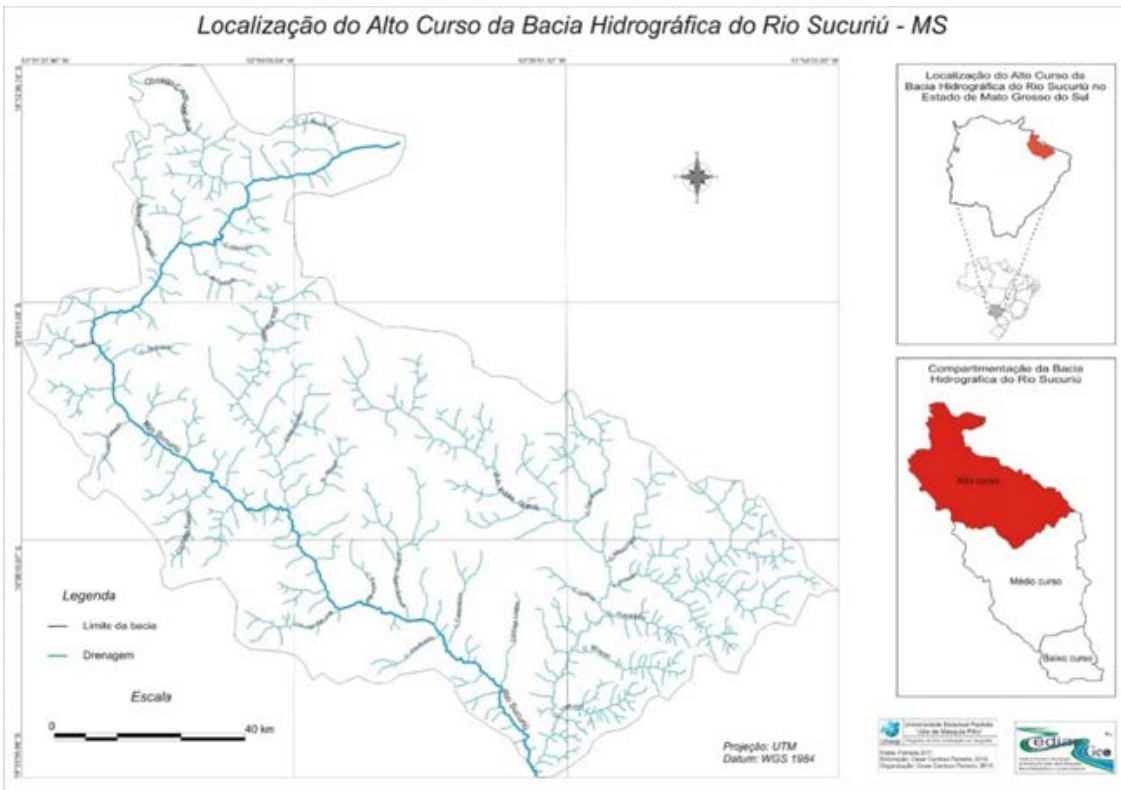

Elaboração: Cesar Cardoso Ferreira.

Para a elaboração do zoneamento ambiental das paisagens da área estudada, foram utilizadas três etapas principais: o inventário/diagnóstico, a correlação/integração e as propostas/prognóstico.

O inventário/diagnóstico constituiu-se do levantamento de dados primários/secundários e de informações relativas à área de estudos relevantes para o cumprimento dos objetivos. Nessa etapa, foi necessária a organização dos dados e informações em banco de dados geográficos para seu armazenamento e manipulação. Este conjunto foi processado no Sistema de Informação Geográfica (SIG) Spring 5.3. O inventário proporcionou a obtenção de elementos para a elaboração do diagnóstico da área de estudo de forma integrada e sistêmica. 
A etapa de correlação e integração dos dados baseou-se na interrelação dos dados secundários e primários para interpretações que subsidiaram a etapa de propostas e prognósticos. Os dados primários basearam-se, especificamente, no uso e cobertura da terra e em informações coletadas nas visitas técnico-científicas em campo. O prognóstico baseou-se nas análises oriundas do diagnóstico, fundamentando o zoneamento ambiental das paisagens.

No zoneamento ambiental das paisagens, foram considerados os aspectos sociais, econômicos e naturais de cada unidade analisada. $\mathrm{Na}$ elaboração da geoecologia da paisagem, seus aspectos e atores foram interpretados e analisados de maneira holística e integrada, com base técnico-científica, instrumental e participativa, o que pode facilitar a implantação de um conjunto de ações e processos de gestão e de desempenho conforme o disposto por Rodríguez e Silva (2013).

Para a classificação da paisagem foi adotada e adaptada a metodologia proposta por Rodríguez, Silva e Cavalcanti (2010), que é baseada na análise paisagística (descrição e classificação) e em investigações geoecológicas (fatores de transformação), visando a organização da paisagem. Logo, a geoecologia da paisagem foi base para as análises socioambientais de forma integrada e sistêmica das unidades de paisagem, considerando os aspectos culturais, sociais, econômicos e naturais.

Tal delimitação paisagística foi feita a partir da sobreposição cartográfica dos aspectos naturais e dos dados fisiográficos e antrópicos com o mapa de uso e cobertura da terra, elaborado com base na classificação das imagens orbitais do satélite Landsat 8, sensor Operational Land Imager (OLI), bandas 4, 5 e 6,do ano de 2014.

À classificação dos dados orbitais foram associadas as descrições das paisagens elaboradas durante as visitas técnico-científicas de campo. Esta etapa teve o objetivo de delimitar as singularidades (paisagens) encontradas nos subsistemas da bacia, que foram denominados de patamares alto, médio e baixo. Posteriormente, foi determinada uma legenda para o mapa da paisagem da área estudada, que é apresentada no Quadro 1.

Quadro 1 - Classificação das paisagens no Alto Curso da Bacia Hidrográfica do Rio Sucuriú.

\begin{tabular}{|l|c|}
\hline Subsistemas & Paisagens \\
\hline \multirow{2}{*}{ Patamar alto } & Vegetação nativa de varjão \\
\cline { 2 - 2 } & Vegetação nativa de cerrado \\
\hline
\end{tabular}




\begin{tabular}{|c|c|}
\hline \multirow{2}{*}{ Patamar médio } & Vegetação nativa de cerrado \\
\cline { 2 - 2 } & Vegetação de cerrado em anfiteatros \\
\cline { 2 - 3 } & Vertentes com argissolos e latossolos, com predomínio de pastagem \\
\hline \multirow{2}{*}{ Patamar baixo } & Vegetação nativa de cerrado \\
\cline { 2 - 3 } & Vegetação de cerrado em anfiteatros \\
\cline { 2 - 3 } & Vertentes com argissolos e latossolos, com predomínio de pastagem \\
\cline { 2 - 3 } & Predomínio de vegetação de pastagem sobre solo arenoso \\
\hline
\end{tabular}

Elaboração: Cesar C. Ferreira e José M. Mateo Rodríguez.

A partir do mapa de paisagens da área de estudo, foi organizado, por meio da análise integrada qualitativa, o mapeamento do zoneamento ambiental das paisagens e feitas as propostas de manejo relacionadas ao uso e cobertura da terra. Na realização do mapeamento foram considerados os aspectos de vulnerabilidade ambiental (potencial da suscetibilidade ambiental), degradação ambiental e relevância econômica (relação da economia com as paisagens), que foram transcritos em uma matriz. Em seguida, após análises referentes às prioridades do ordenamento territorial, foram adotadas classificações para as unidades de paisagens baseadas na legenda proposta por Rodriguez, Silva e Cavalcanti (2010) e adaptada para a realidade do alto curso da bacia hidrográfica do rio Sucuriú (Quadro 2).

Quadro 2 - Legenda do zoneamento ambiental das paisagens da área de estudo.

\begin{tabular}{|c|c|}
\hline Legenda & Contexto \\
\hline Reabilitação & Mudança completa do uso atual, reabilitando para um alto valor ambiental. \\
\hline Regeneração & $\begin{array}{r}\text { Manter a feição de uso e função atual, mas intervir ambientalmente dando preferência ao } \\
\text { valor ambiental. }\end{array}$ \\
\hline Melhoramento & $\begin{array}{c}\text { Otimizar a feição de uso atual através do emprego de técnicas para selecionar melhores } \\
\text { alternativas para atingir os objetivos do fluxo funcional, sem perder o valor ambiental. }\end{array}$ \\
\hline Aproveitamento & $\begin{array}{c}\text { Aproveitar melhor a atual feição de uso, intercalando com outros usos funcionais e/ou } \\
\text { ambientais. }\end{array}$ \\
\hline Conservação & Prosseguir com as funções atuais, mas mantendo o estado atual. \\
\hline Preservação & Manter protegido de intervenções antrópicas e possíveis danos ambientais. \\
\hline
\end{tabular}

Organização: Cesar Cardoso Ferreira. Fonte: Rodriguez (2010) editado por Braz et al. (2015).

As classes do zoneamento ambiental das paisagens foram vinculadas à propostas pontuais associadas à reorganização do manejo do uso e cobertura da terra da área de estudo à vista do equilíbrio socioambiental. Na sequência, as informações das matrizes foram espacializadas gerando o mapa de zoneamento ambiental das paisagens da área de estudo. 
Os procedimentos supracitados partiram da necessidade de integrar e correlacionar dados e informações sobre a área e associar a uma temática, propondo um modelo de análise ambiental sistêmica para o ordenamento territorial baseado na preservação, conservação, melhoramento, aproveitamento, regeneração e reabilitação das paisagens da área.

\section{Resultados}

A partir da metodologia apresentada, do inventário/diagnóstico e da correlação/integração de dados físicos naturais e antrópicos analisados sistematicamente, delineiam-se os resultados obtidos nesse trabalho. As análises qualitativas cartográficas temáticas da bacia associadas às visitas técnico-científicas de campo permitiram a elaboração do mapa das paisagens da área, por meio de informações organizadas em uma matriz com intuito de integrar e correlacionar dados referentes aos aspectos físicos naturais e antrópicos da bacia. Este procedimento resultou em três áreas significativamente homogêneas determinadas como subsistemas e classificadas como: patamar alto, patamar médio e patamar baixo localizados em clima com características de úmido e sub-úmido, conforme apresentado na Figura 2.

Figura 2 - Matriz da Paisagem da área de estudo.

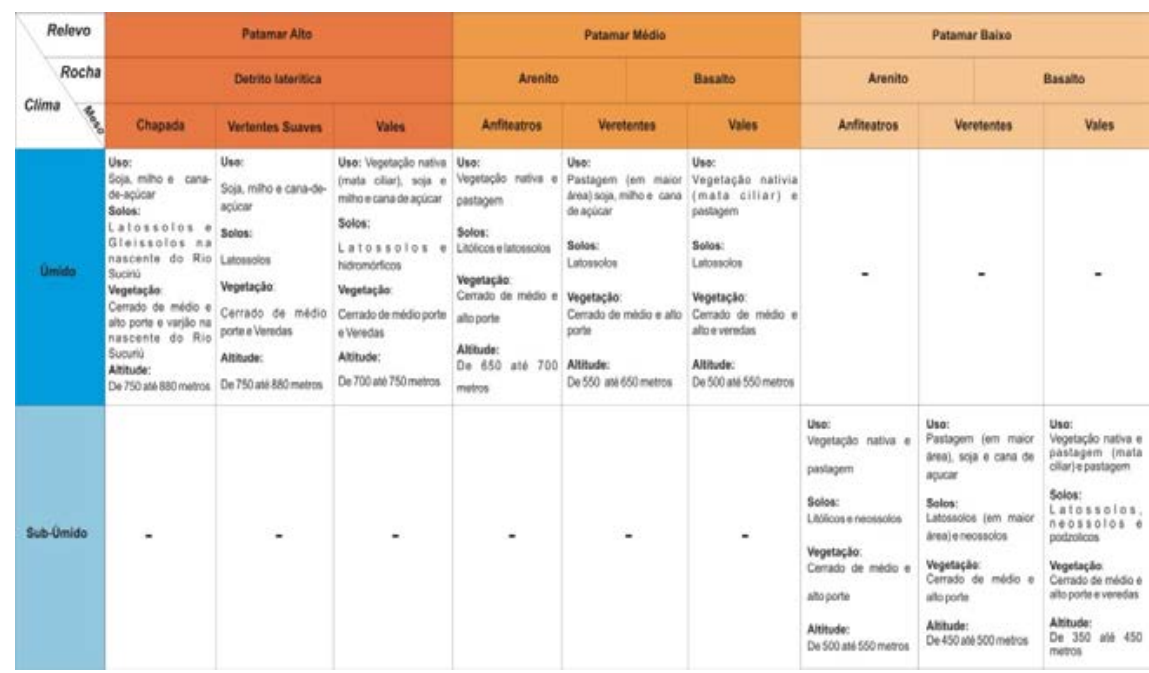

Elaboração: Cesar C. Ferreira, José M. Mateo Rodríguez. 
Na Figura 3 é mostrado o mapa das paisagens da área de estudo, onde é possível observar que os patamares altos estão predominantemente sobre rochas detrito lateríticas e em região com clima úmido. São subdivididos em três partes componentes denominadas de unidades paisagísticas: chapada, vertentes suaves e vales. Os patamares médios estão localizados sobre rochas de arenito e basalto e clima úmido, subdivididos em três unidades de paisagem: anfiteatros, vertentes e vale. Os patamares baixos estão situados sobre rochas de arenito e basalto em clima sub-úmido, subdivididos em três unidades de paisagem: anfiteatros, vertentes e vales.

Figura 3 - Mapa da paisagem do alto curso da bacia hidrográfica do rio Sucuriú.

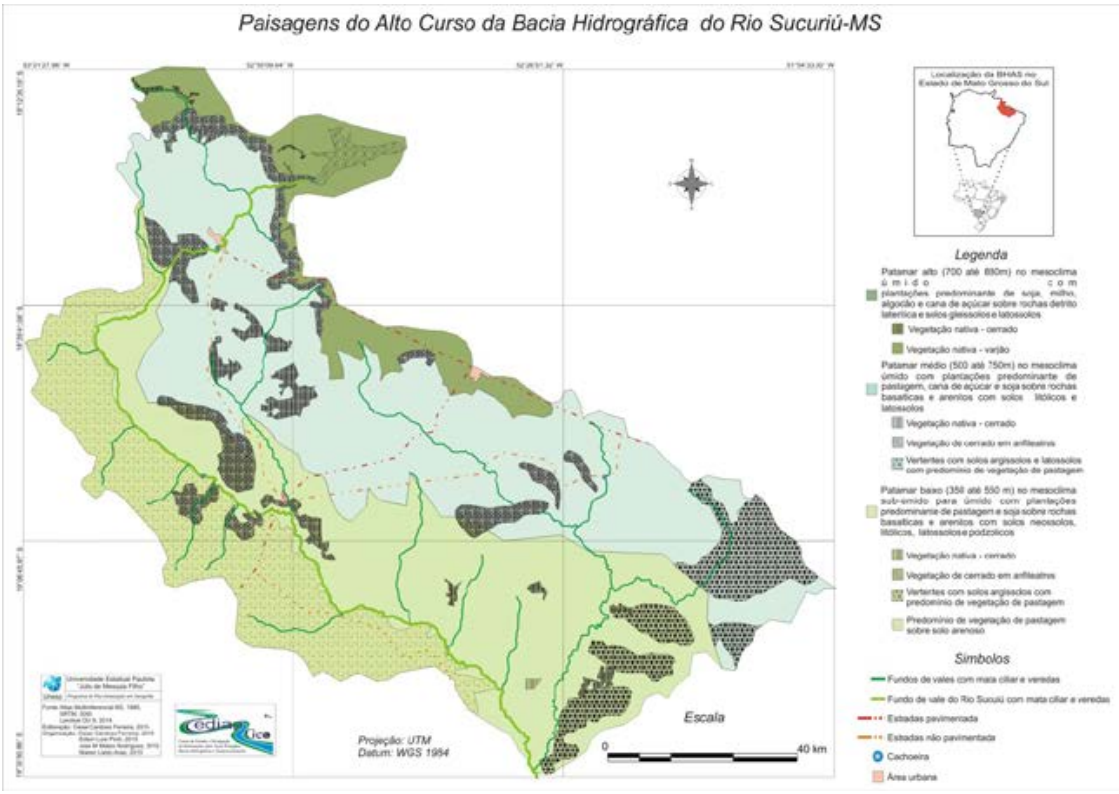

Elaboração: Cesar C. Ferreira, José M. Mateo Rodríguez e Edson L. Piroli.

Para o zoneamento ambiental das paisagens da área, baseou-se, além do mapa apresentado na Figura 3, em uma matriz com o detalhamento organizado de informações relevantes para a determinação das classes do zoneamento ambiental que é demonstrada na Figura 4. 
Figura 4 - Matriz do zoneamento ambiental das paisagens da área de estudo.

\begin{tabular}{|c|c|c|c|c|c|c|c|c|c|c|}
\hline \multicolumn{2}{|r|}{ Unidades } & \multicolumn{2}{|c|}{ Temas - Paisagens } & \multicolumn{2}{|c|}{ Ternas - Geoambientais } & \multirow{2}{*}{$\begin{array}{c}\begin{array}{c}\text { Fator } \\
\text { económico }\end{array} \\
\text { importincio }\end{array}$} & \multicolumn{4}{|c|}{ Zoneamento } \\
\hline Patamar & Classe & Viherabildade & Degradacdo & Vulherabidacte & $\begin{array}{l}\text { Probebilidade } \\
\text { degradaglo }\end{array}$ & & Zonas & & & Deseriedo \\
\hline \multirow{2}{*}{ Allo } & Vegetachlo cerrado & Intergrade & Baica & $\begin{array}{l}\text { Moseradarnemto } \\
\text { instavel }\end{array}$ & Baca & Baixa & Preservacalo & $\begin{array}{l}\text { Manter prote } \\
\text { ambierese. }\end{array}$ & das do inter & 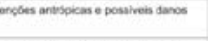 \\
\hline & Vogetaça varito & Intergrade & Mécia & $\begin{array}{l}\text { Moseracamense } \\
\text { instaved }\end{array}$ & Bocea & Baixa & Preservacto & $\begin{array}{l}\text { Manter prote } \\
\text { menbientais. }\end{array}$ & So do interen & encless amopicas e positives danos \\
\hline \multirow{3}{*}{ Moso } & Vegetaglo certado & Intergrade & Baixa & $\begin{array}{l}\text { Moderadamentso } \\
\text { instivivel }\end{array}$ & Baca & Basa & Preservacio & $\begin{array}{l}\text { Manter prote } \\
\text { movietras. }\end{array}$ & SSo do inten & ancebes antaspican e postiven danos \\
\hline & $\begin{array}{l}\text { Vegetacto cerrado } \\
\text { em ansioatros }\end{array}$ & $\begin{array}{c}\text { Moderadanente } \\
\text { nstivet }\end{array}$ & Multo Baba & Instiver & Baika & Baixa & Preservacto & $\begin{array}{l}\text { Morter srowe } \\
\text { anbientass. }\end{array}$ & dos do interent & ongoes antropicas e postives danos \\
\hline & 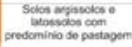 & $\begin{array}{l}\text { Moderadinente } \\
\text { nsthvel }\end{array}$ & Mecia & Intargrace & Muto Ala & NeO & Methoramento & 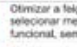 & 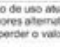 & 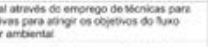 \\
\hline \multirow{4}{*}{8000} & Vegetacklo cerrado & Intergrade & Baica & instave & Aaca & Baixa & Prosenvacalo & $\begin{array}{l}\text { Manter prote } \\
\text { ambientas. }\end{array}$ & doo do inter & 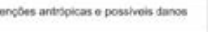 \\
\hline & $\begin{array}{l}\text { Vegetacto certado } \\
\text { em antiveatros }\end{array}$ & Intergrade & Muilo Baxa & Intergrace & Baxa & Basxa & Preservacio & $\begin{array}{l}\text { Merte prove } \\
\text { ambientiak. }\end{array}$ & bo de intare & 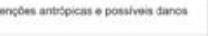 \\
\hline & 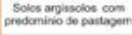 & $\begin{array}{l}\text { Modorsdumerte } \\
\text { instavel }\end{array}$ & Mécie & Intavel & Muto AVta & Nea & Rasubilacas & $\begin{array}{l}\text { Muderca co } \\
\text { sara un ato }\end{array}$ & $\begin{array}{l}\text { dabta da sely } \\
\text { abor ambier }\end{array}$ & 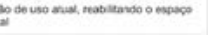 \\
\hline & $\begin{array}{l}\text { Soldos avenosios corm } \\
\text { predcriniso de pantapem }\end{array}$ & instavel & Aka & Instave & Muto AEs & Nea & Roubitscan & $\begin{array}{l}\text { Mudsonga co } \\
\text { sara um ahe }\end{array}$ & 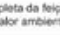 & Do de uno anat, reabiatendo o espasp \\
\hline \multicolumn{11}{|c|}{ Feiçóes } \\
\hline Funso \& & $\begin{array}{l}\text { do vales com mata sear } \\
\text { overedas }\end{array}$ & $\begin{array}{l}\text { Moderadomersto } \\
\text { nstavel }\end{array}$ & Baica & $\begin{array}{l}\text { Moderatamento } \\
\text { instivel }\end{array}$ & Bacea & Baba & Proservacio & \multicolumn{3}{|c|}{ 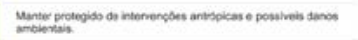 } \\
\hline $\begin{array}{l}\text { Fundod } \\
\text { com: }\end{array}$ & $\begin{array}{l}\text { ido valh do Rio Suains } \\
\text { math ofier everedas }\end{array}$ & Intergrade & Baica & Instargrace & Baca & Baixa & Conservacto & \multicolumn{3}{|c|}{ Prossegur corm as unples atuss, mas mantindo o estaco atud } \\
\hline Estras & Sas nabs pavimentadas & $\begin{array}{l}\text { Moderadamentio } \\
\text { nutavel }\end{array}$ & Ata & $\begin{array}{l}\text { Moderadamence } \\
\text { instaved }\end{array}$ & Muto Als & Nea & Rextiltacat & \multicolumn{3}{|c|}{ 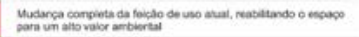 } \\
\hline & radas parimereadss & $\begin{array}{l}\text { Moderadarnerto } \\
\text { nstavive }\end{array}$ & Baixa & $\begin{array}{l}\text { Moseradarmenses } \\
\text { instavei }\end{array}$ & Baica & Nes & Regtnerachs & \multicolumn{3}{|c|}{ 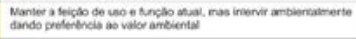 } \\
\hline & Cachoeven & Intergrade & Baixs & Intergrace & Avica & Mesa & Aprovelamerto & \multicolumn{3}{|c|}{ 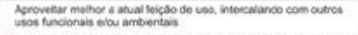 } \\
\hline & Ares Urteara & $\begin{array}{l}\text { Moderadameste } \\
\text { nstavel }\end{array}$ & Aasa & $\begin{array}{l}\text { Moderadamenses } \\
\text { instaver }\end{array}$ & Ala & Nata & Melhoramento & \multicolumn{3}{|c|}{ 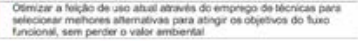 } \\
\hline Proserv & vagalo & Regeneracks & & \multirow{3}{*}{\multicolumn{5}{|c|}{ 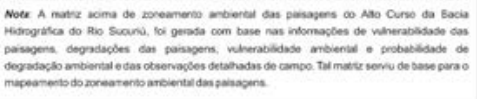 }} & $\log$ & 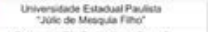 \\
\hline Consev & vacto & Mehoramento & & & & & & & Tomenge & 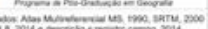 \\
\hline Aproverara & amereco & Reubetacto & & & & & & & gances: & 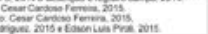 \\
\hline
\end{tabular}

Elaboração: Cesar Cardoso Ferreira.

Na área de estudo as zonas de preservação estão associadas à vegetação de cerrado, vegetação de varjão e às matas ciliares, portanto é necessário mantê-las protegidas de intervenções antrópicas e de possíveis danos ambientais. As zonas de melhoramento estão associadas ao cultivo de pastagem em argissolos e nas áreas urbanas onde sugere-se a otimização da feição de uso atual sem perder o valor ambiental. As zonas de reabilitação são as mais problemáticas e estão associadas à produção de pastagem em neossolos e nas estradas não pavimentadas. Neste caso indica-se a mudança completa da feição de uso atual, reabilitando o espaço para um valor ambiental maior. As zonas de conservação estão associadas às matas ciliares do rio Sucuriú e de seus afluentes. Assim, sugere-se prosseguir com as funções atuais, mantendo o estado atual.

As zonas de regeneração foram associadas às rodovias pavimentadas. Nestes locais indica-se manter a feição de uso e a função atual, mas também a intervenção ambiental visando a proteção dos recursos naturais 
do seu entorno. A zona de aproveitamento está localizada nas cachoeiras e nos pontos com potencial turístico. Nela se recomenda o melhor aproveitamentoda atual da feição de uso, intercalando com outros usos funcionais e/ou ambientais. As classes supracitadas são demonstradas na Figura 5.

Figura 5 - Mapa de zoneamento ambiental das paisagens da área de estudo.

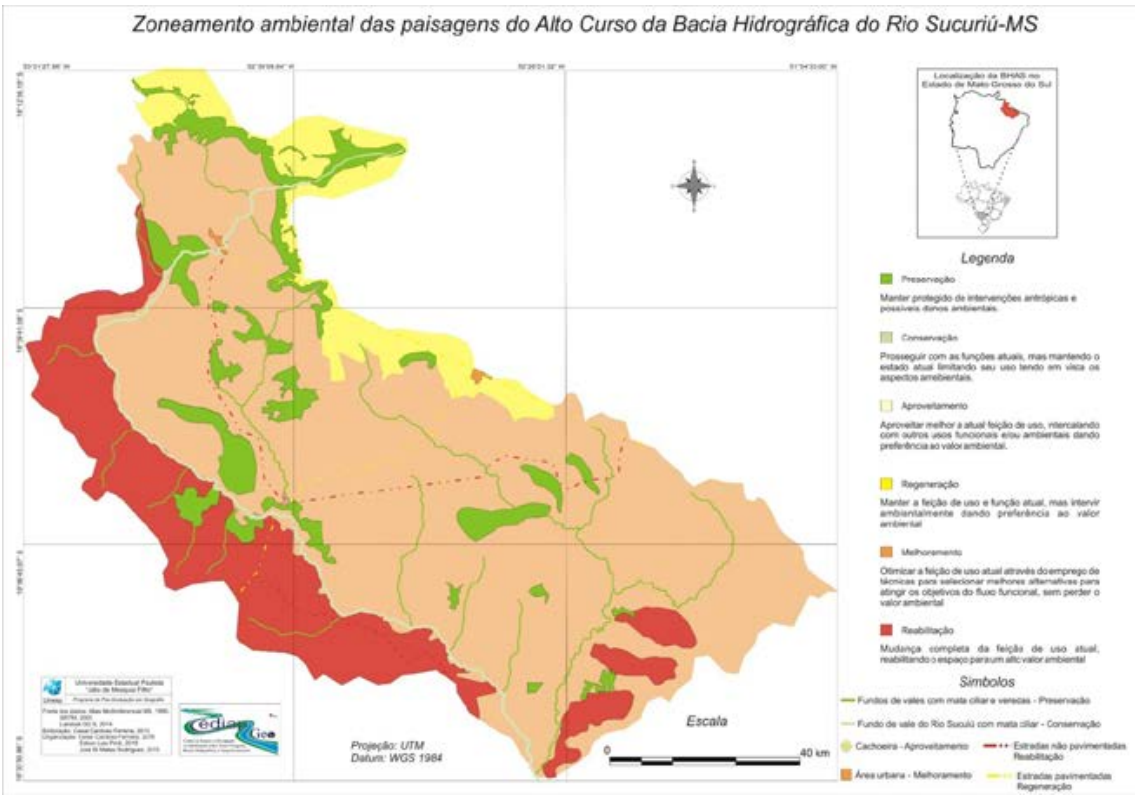

Elaboração: Cesar Cardoso Ferreira.

Em associação ao zoneamento ambiental das paisagens é proposto o manejo da bacia baseado no uso do solo e na cobertura da terra, e considerando as características fisiográficas predominantes, tendo em vista as alterações ambientais observadas em campo e na distribuição espacial da vulnerabilidade ambiental da bacia, priorizando a conservação ambiental associada ao desenvolvimento agrícola e econômico.

A partir destas premissas, foram elaboradas as propostas de manejo de uso da terra associadas ao zoneamento ambiental das paisagens da área apresentadas no Quadro 3. 
Quadro 3 - Propostas para o manejo no uso da terra da área estudada.

\begin{tabular}{|c|c|c|}
\hline $\begin{array}{c}\text { Uso e } \\
\text { cobertura } \\
\text { da terra }\end{array}$ & Ações & Benefícios \\
\hline 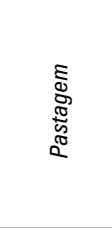 & $\begin{array}{l}\text { - lotação adequada de gado com rotatividade de pastos; } \\
\text { - utilização de espécies forrageiras adequadas; } \\
\text { - isolamento das APP; } \\
\text { - implantação de terraços em nível; } \\
\text { - correção da fertilidade do solo; } \\
\text { - adoção de sombreamento dos pastos; } \\
\text { - uso de sistemas silvopastoris. }\end{array}$ & $\begin{array}{l}\text { Redução do pisoteio do gado e } \\
\text { de erosões, redução de espécies } \\
\text { invasoras, manutenção e } \\
\text { preservação das APP, redução da } \\
\text { compactação e da contaminação do } \\
\text { solo, com aumento da infiltração e } \\
\text { conforto térmico para os animais. }\end{array}$ \\
\hline 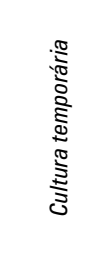 & $\begin{array}{c}\text { - adoção do plantio direto; } \\
\text { - implantação da agricultura de precisão; } \\
\text { - construção de terraços em nível; } \\
\text { - rotação de culturas; } \\
\text { - diversificação de culturas; } \\
\text { - controle e uso adequado de agroquímicos; } \\
\text { - adequação das culturas à capacidade de uso das terras; } \\
\text { - adoção de técnicas de infiltração de água no solo. }\end{array}$ & $\begin{array}{l}\text { Redução da compactação do solo, } \\
\text { aumento da infiltração de água, } \\
\text { economia de insumos agrícolas, } \\
\text { redução de erosões, manutenção } \\
\text { da fertilidade e extinção da } \\
\text { contaminação do solo. }\end{array}$ \\
\hline 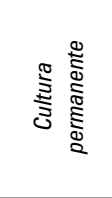 & $\begin{array}{c}\text { - intercalação de espécies no espaço; } \\
\text { - rotatividade de espécies; } \\
\text { - escalonamento da produção no tempo; } \\
\text { - incentivos à criação de corredores ecológicos; } \\
\text { - usos múltiplos dos plantios; } \\
\text { - uso de sistemas agrosilvopastoris. }\end{array}$ & $\begin{array}{l}\text { Diversificação de uso e aumento } \\
\text { de produtividade, promover a } \\
\text { conectividade entre fragmentos } \\
\text { de áreas naturais e usos múltiplos } \\
\text { otimizando espaços improdutivos e } \\
\text { impactados. }\end{array}$ \\
\hline 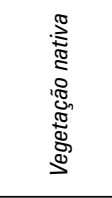 & $\begin{array}{c}\text { - preservação, conservação e recuperação; } \\
\text { - atendimento da legislação relativa às APP's e Reservas } \\
\text { Legais; } \\
\text { - usos múltiplos das áreas de florestas nativas; } \\
\text { - implantação de corredores ecológicos; } \\
\text { - implantação de sistema de monitoramento. }\end{array}$ & $\begin{array}{l}\text { Aumento da biodiversidade e da } \\
\text { produtividade, com impacto positivo } \\
\text { sobre a água, o solo, a fauna } \\
\text { silvestre e o microclima regional. }\end{array}$ \\
\hline$\stackrel{\mathbb{3}}{\stackrel{5}{+}}$ & $\begin{array}{c}\text { - preservação e recuperação das APP's; } \\
\text { - determinar áreas de infiltração e recarga dos aquíferos; } \\
\text { - incentivar a ampliação das áreas de recarga; } \\
\text { - Implantar projetos de saneamento básico das } \\
\text { residências e áreas urbanas; } \\
\text { - combater o assoreamento dos corpos d'água; } \\
\text { - criar estações de monitoramento físico-químico e } \\
\text { hidráulico dos principais recursos hídricos; } \\
\text { - não implantar novas PCH's; } \\
\text { - Incentivar os usos múltiplos das PCH's já existentes; } \\
\text { - incentivar projetos de proteção e conservação das } \\
\text { águas. }\end{array}$ & $\begin{array}{l}\text { Melhoramentos nas condições } \\
\text { físico-químicas ambientais } \\
\text { das águas e aumento de áreas } \\
\text { destinadas ao lazer, com a proteção } \\
\text { dos recursos hídricos, visando } \\
\text { sua perpetuação em qualidade e } \\
\text { quantidade. }\end{array}$ \\
\hline
\end{tabular}




\begin{tabular}{|c|c|c|}
\hline 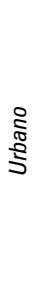 & $\begin{array}{c}\text { - implantação de redes de coleta e tratamento de esgoto; } \\
\text { - implantação de redes de coleta e tratamento de água } \\
\text { pluvial; } \\
\text { - disciplinar o uso do solo urbano com aumento de áreas } \\
\text { permeáveis; } \\
\text { - implantação de galerias pluviais; } \\
\text { - implantação de educação ambiental; } \\
\text { - incentivar projetos de manejo de microbacias } \\
\text { hidrográficas urbanas. }\end{array}$ & $\begin{array}{c}\text { Melhorar as condições de habitação, } \\
\text { e as condições ambientais em áreas } \\
\text { urbanas, protegendo os recursos } \\
\text { naturais e a vida e o patrimônio das } \\
\text { pessoas. }\end{array}$ \\
\hline
\end{tabular}

Elaboração: Cesar Cardoso Ferreira e Edson Luís Piroli.

Este conjunto de sugestões parte do princípio de que a área seja manejada de acordo com os fundamentos do manejo integrado de bacias hidrográficas, uma vez que este visa tornar compatível a produção com a preservação ambiental, buscando adequar a interveniência antrópica às características biofísicas dessas unidades naturais (ordenamento do uso/ocupação da paisagem, observadas as aptidões de cada segmento e sua distribuição espacial na respectiva bacia hidrográfica), sob gestão integrativa e participativa, de forma que sejam minimizados impactos negativos e se garanta o desenvolvimento sustentado (Souza; Fernandes, 2000).

Para isto, o uso dos solos de acordo com sua capacidade é o ponto de partida para o desenvolvimento de atividades produtivas de maneira sustentada, atendendo a geração atual e perpetuando o potencial de produção de alimentos e matérias primas para as gerações vindouras e para os demais seres vivos (Piroli, 2002).

Este uso deve ser fundamentado na capacidade de uso da terra que pode ser conceituada como a adaptabilidade da terra às diversas formas de utilização agrícola, sem que ocorra o depauperamento do solo pelos fatores de desgaste e empobrecimento, por meio de seu uso (Lepsch et al., 1991).

Portanto, antes de ser adotado um programa de conservação do solo, é necessário determinar a capacidade de uso da terra, em função de que esta permita estabelecer bases para o seu melhor aproveitamento, sem sofrer depauperamento pelos fatores de degradação (Giboshi et al., 2006).

Outra proposta de manejo voltada às infraestruturas de transporte, principalmente nas vias não pavimentadas, é baseada no "Programa Melhor Caminho", instituído pelo Decreto nº 41.721 de 17 de abril de 1997, destinado à elaboração de convênios entre a Secretaria de Agricultura e Abastecimento do Estado de São Paulo, que determina a readequação das plataformas das estradas rurais de terra, com ou sem a elevação do 
"greide estradal”, para a implantação de sistema de drenagem superficial eficiente (Estado de São Paulo, 1997).

Além disso, recomenda-se usar pontos de sangra da estrada (deságue), para evitar a ocorrência de processos erosivos nas propriedades lindeiras e terraços ou bacias de captação para facilitar a infiltração das águas pluviais e a recarga do lençol freático. Esse conjunto de propostas trará como benefícios estradas de terra com boas condições operacionais e de conforto, segurança e trafegabilidade aos usuários, e a preservação dos recursos naturais - especialmente a água e o solo - reduzindo os efeitos dos processos erosivos e o assoreamento dos cursos d'água, com redução dos custos dos transportes dos insumos e da produção agrícola.

A partir de trabalhos deste tipo é possível organizar sistemas de informação sobre os recursos hídricos e sobre as demais características fisiográficas, sociais e econômicas, para o armazenamento e difusão de maneira descentralizada das informações geradas para toda a sociedade. Estes sistemas devem incluir e manter atualizado um banco de dados com todos os resultados de estudos já realizados e em realização, em especial na bacia do rio Sucuriú, visando orientar os processos de tomada de decisões e a manutenção ou melhoria da qualidade ambiental da área.

\section{Considerações Finais}

A partir das análises elaboradas e dos resultados obtidos, pode-se afirmar que o zoneamento ambiental das paisagens tem potencial para auxiliar nas tomadas de decisões referentes à gestão ambiental de bacias hidrográficas. Este zoneamento pode servir como base para o planejamento ambiental, permitindo a definição de metas e planos baseados em ações que visem orientar o uso e cobertura da terra e seu manejo em vista da vulnerabilidade ambiental natural de cada região de interesse.

Pode-se afirmar, também, que a preocupação relacionada ao equilíbrio entre desenvolvimento econômico e ambiental deve estar associada à preservação e à conservação das paisagens naturais da área de estudo. Como exemplo de áreas a serem preservadas, citam-se as veredas, as matas ciliares, os anfiteatros, os remanescentes de cerrado, os rios e as cachoeiras. Essas unidades, além de ter importantes funções ecológicas, representam a possibilidade de interação entre homem e natureza com intuito, por exemplo, educacional e informacional. 
A categoria paisagem utilizada como base para o presente estudo, permitiu o entendimento da funcionalidade dos ambientes naturais e antrópicos do alto curso da bacia hidrográfica do rio Sucuriú, e a elaboração do zoneamento ambiental das paisagens. Por sua vez, o zoneamento possibilitou a compreensão das restrições, potencialidades e reabilitações que ocorrem na área. Isto permitiu que fossem elaboradas propostas pontuais para o manejo do uso da terra da área.

A abordagem sistêmica foi de fundamental importância como apoio para a análise integrada aplicada para o zoneamento ambiental das paisagens, na obtenção dos resultados e na correlação dos mesmos, além da associação de todos os resultados obtidos, que podem ser vistos de forma holística e servir de base para a elaboração das propostas de planejamento para o uso a terra da área estudada.

Associado à base teórica-metodológica, o suporte tecnológico fundamentado no sensoriamento remoto e no geoprocessamento, permitiu a aplicação do método e a obtenção dos resultados da pesquisa, deixando evidente sua eficiência. Por conseguinte, possibilitou a aquisição, manipulação, processamento e armazenamentos dos dados da área de estudo, que foram transformados em informações que podem ser usadas pelo poder público e por outras pessoas interessadas na preservação, proteção e recuperação da área.

Por fim, os estudos realizados demonstraram a importância de se conhecer prévia e detalhadamente o meio físico e antrópico das áreas analisadas. Nesse caso, a partir da análise sistêmica integrada com modelagens ambientais associadas às geotecnologias em análises da paisagem, foi possível gerar seu zoneamento ambiental para fins de tomadas de decisão relacionadas à conservação dos recursos naturais e à revitalização de áreas deficientes associadas à produção agrícola-industrial e aos espaços de lazer.

\section{Referências}

ÁGUAS, T. A. Análise ambiental nas áreas de influência direta e indireta da PCH Costa Rica, no alto curso da bacia hidrográfica do rio Sucuriú - MS/2014. 2015. 127f. Dissertação (Mestrado em Geografia) - Universidade Federal de Mato Grosso do Sul - Três Lagoas, 2015. 
BERTALlAnFY, L. V. Teoria Geral dos Sistemas. Petrópolis: Editora Vozes, 1977.

BRAZ, A. M.; SOKOLOWSKI, H. G. S.; FERREIRA, L. A.; RODRIGUEZ, J. M. M. Diagnóstico ambiental e planejamento da paisagem sob uma perspectiva sistêmica: estudo da mineração de areia e brita no Rio Paraná, município de Três Lagoas (MS). Revista Eletrônica da AGB, Seção Três Lagoas, v. 1, p. 121-155, 2015.

CHRISTOFOLETTI, A. Modelagem de Sistemas Ambientais. São Paulo: Edgard Blucher, 1999.

FERREIRA, C. C. Proposta de zoneamento ambiental das paisagens para o Alto Curso da Bacia Hidrográfica do Rio Sucuriú, Mato Grosso do Sul-Brasil. 2015. 211f. Tese (Doutorado em Geografia) - Universidade Estadual Paulista, Presidente Prudente, 2015.

GIBOSHI, M. L.; RODRIGUES, L. H.; LOMBARDI NETO, F. Sistema de suporte à decisão para recomendação de uso e manejo da terra. Revista Brasileira de Engenharia Agrícola e Ambiental, v. 10, n. 4, p. 861-866, 2006.

LEPSCH, I. F.; BELLINAZI JR., R; BERTOLINI, D.; ESPÍNDOLA, C.R. Manual para levantamento utilitário do meio físico e classificação de terras no sistema de capacidade de uso. 4a Aproximação. 2.ed. Campinas: Sociedade Brasileira de Ciência do Solo, 1991.

MANOSSO F. C. Estudo integrado da paisagem nas regiões norte, oeste e centrosul do Estado do Paraná: relações entre a estrutura geoecológica e a organização do espaço. Boletim de Geografia - UEM, v. 26/27, n. 1, 2009.

PIROLI, E. L. Geoprocessamento na Determinação da Capacidade e Avaliação do uso da Terra no Município de Botucatu-SP. 2002. 122f. Tese (Doutorado) Universidade Estadual Paulista, Botucatu, 2002.

QUIRINO P. B.; ROCHA M. B.; MOURA L. M. M. Paraíso das Águas... e o lixo? IX Fórum Ambiental da Alta Paulista, v. 9, n. 4, 2013.

RODRIGUEZ, J. M. M.; SILVA, E. V.; CAVALCANTI, A. P. B. Geoecologia das paisagens: uma análise ambiental. Fortaleza: Ed. UFC, 2010.

RODRIGUEZ, J. M. M. e SILVA, E. V. Planejamento e gestão ambiental: subsídios da geoecologia das paisagens e da teoria geossistêmica. Fortaleza: Ed. UFC, 2013.

SÃO PAULO (ESTADO). Decreto n. 41.721, de 17 de abril de 1997. Institui o Programa "Melhor Caminho" e estabelece diretrizes para sua execução. Assembleia Legislativa do Estado de São Paulo. Diário Oficial do Estado de São Paulo, São Paulo: 1997.

SILVA. E. V. e RODRIGUEZ, J. M. M. Geoecologia da Paisagem: Zoneamento e Gestão Ambiental em Ambientes Úmidos e Subúmidos. Revista Geográfica de América Central, v. 2, n. 47E, 2011.

SILVA R. A.; PIRES E. V. R.; IZIPPATOF. J.; MIRANDOLA P. H. Geoprocessamento aplicado a análise do uso e ocupação da terra e APPs de nascentes no rio Indáia Grande - Chapadão do Sul/Cassilândia/Inocência (MS). Revista GEONORTE, Ed. Especial, v. 2, n.4, p.1497-1508, 2012. 
SIQUEIRA, R. M. B.; SILVA G. H. A bacia hidrográfica como unidade de estudo e o funcionamento dos ecossistemas fluviais. Boletim da Associação Brasileira de Limnologia, v. 39, n. 2, p. 1-15, 2011.

SOUZA, E. R.; FERNANDES, M. R. Sub-bacias hidrográficas: unidades básicas para o planejamento e a gestão sustentáveis das atividades rurais. Informe Agropecuário, Belo Horizonte, v. 21, n. 207, p. 15-20, 2000.

VALENTE, R. O. A. Definição de áreas prioritárias para conservação e preservação florestal por meio da abordagem multicriterial em ambiente SIG. 2005. 121f. Tese (Doutorado) - ESALQ/Universidade de São Paulo, Piracicaba, 2005.

Cesar Cardoso Ferreira - Possui Graduação e Mestrado pela Universidade Federal de Mato Grosso do Sul e Doutorado pela Universidade Estadual Paulista de Presidente Prudente. Atualmente é Técnico em Cartografia pela Universidade Federal de Mato Grosso do Sul.

Edson Luis Piroli - Possui Graduação em Engenharia Florestal pela Universidade de Santa Maria, Mestrado em Engenharia Agrícola pela mesma universidade. É doutor em Agronomia pela Universidade Estadual Paulista de Presidente Prudente. Atualmente é professor adjunto na Universidade Estadual Paulista.

Contribuição de cada autor no desenvolvimento do artigo:

Ambos os autores foram responsáveis conjuntamente por todas as etapas desde o desenho conceitual e teórico metodológico até a análise e interpretação dos resultados.

Recebido para publicação em 5 de fevereiro de 2016 Aceito para publicação em19 de março de 2016 
